\title{
Correction to: Overweight adolescents' views on physical activity - experiences of participants in an internet-based intervention: a qualitative study
}

Turid Kristin Bigum Sundar ${ }^{1 *}$ (D, Knut Løndal ${ }^{2,3}$, Per Lagerløv ${ }^{1}$, Kari Glavin ${ }^{4}$ and Sølvi Helseth ${ }^{2,3}$

\section{Correction to: BMC Public Health (2018) 18: 448.} https://doi.org/10.1186/s12889-018-5324-x

In the original version of this article [1], published on 4 April 2018, there was 1 incorrect author family name. The redundant affiliation (5) has also been removed. The original article has been updated.

The incorrect author name was published as:

- Kari Galvin

The correct author name are:

- Kari Glavin

The original publication of this article has been corrected.

\section{Author details}

'Department of General Practice, Institute of Health and Society, Faculty of Medicine, University of Oslo, Oslo, Norway. ${ }^{2}$ Department of Nursing and Health Promotion, Faculty of Health Sciences, OsloMet - Oslo Metropolitan University, Oslo, Norway. ${ }^{3}$ Department of Primary and Secondary Teacher Education, Faculty of Education and International Studies, OsloMet -Oslo Metropolitan University, Oslo, Norway. ${ }^{4}$ IID Specialized University, Oslo, Norway.

Published online: 14 May 2018

\section{Reference}

1. Sundar TKB, Løndal K, Lagerløv P, et al. BMC Public Health. 2018;18(448)

https://doi.org/10.1186/s12889-018-5324-x

\footnotetext{
* Correspondence: t.k.b.sundar@studmed.uio.no

'Department of General Practice, Institute of Health and Society, Faculty of Medicine, University of Oslo, Oslo, Norway
} 